\title{
Study on the Modernization of Educational Governance under the Background of Big Data
}

\author{
Yi Zhou \\ Chengdu Institute of Education Sciences, Chengdu, Sichuan, 610000
}

Keywords: Big Data, Education Governance, Modernization

\begin{abstract}
In the context of the vigorous development of Internet + and large data, the state is actively promoting education management to education governance, so the analysis of educational information service model of the new development has a positive role and significance. Based on the theory and practice of different countries in the world, this paper analyzes the existing different types of educational information service modes, and analyzes the problems existing in the research and practice of the existing educational information public service in our country. The development of educational information technology development service system is not enough, and the gap between the developed areas is large, the top design is insufficient, the system design is not enough and the evaluation system is still imperfect, weak impact. This paper argues that building a public service system of educational information in the context of educational governance modernization needs to pay attention to the task of educational information development under the educational public service, straighten out the diversified participatory orientation, innovation management and operation mechanism under the public - private partnership mode, do a good job in system construction.
\end{abstract}

\section{Introduction}

From the countries attach importance to the actual situation of information technology education applications, the use of technical means to support education management and education has become the norm of educational development. Education information has a wide range of service functions in education management, teaching support, learning services and lifelong learning while facing the teachers and students of the university and the majority of social learners. With the process of modernization of educational governance, educational informationization has also been given an important position, and it will also play an important supporting role in the construction of a new type of educational modernization system with service openness, type diversity and structural rationality as the basic characteristics. In the past two years, there has been a strong interest in new applications based on "Internet +" and "Big Data", and governments, businesses and social institutions have explored many of them. The general view is that the potential value of these new application models is immeasurable. Although the new technology has inherent advantages, "blind worship and chase the trend" is not desirable. By analyzing the relevant policy documents issued by the government in recent years and the related scientific research results published by academic institutions, this paper has found that planning and designing the work of education informatization to follow and truly reflect the essence of "service" and not get the manager And the researchers' attention. Many researchers lack the rational thinking based on the main contradiction of contemporary education development in China, and the government is not enough to explore the construction of educational information service system, especially the idea of "modern education governance" and realize "education management to education governance" change lack of systematic research. 


\section{The Significance of Big Data to the Modernization of Educational Governance}

The optimization of educational governance authority is one of the opportunities for large data to enhance the ability of education and management. In the context of large data, the government, schools and social organizations in the education and management of the powers and responsibilities have been further optimized, which is conducive to the government, schools and social organizations to achieve in the educational governance function of cooperation and cooperation to promote education and management capacity of the whole Ascension. On the one hand, through the collection and processing of large data, the government concentrates on the macro-control and planning of public affairs of education, which will delegate the micro-processing power to the school or transfer to the social organization, and proceed to the field of educational governance supervision and coordination, and bear the corresponding macro-regulatory responsibilities; the other hand, in the context of large data, schools and social organizations as an important source of education and management of important sources, need to actively cooperate with the government in the field of education and macroeconomic regulation and control, the government collects, excavates, analyzes and deals with the relevant educational governance data, sends the important data information of the micro-field of education governance to the government in time and accurately, and carries on the corresponding micro-autonomy responsibility on the basis of realizing the self-management of the micro-field of education governance. In the process of dealing with large data, the government, schools and social organizations are optimized in the area of power and responsibility to further promote the transformation of government administrative functions and improve the ability of schools and social organizations to participate in education governance, the complementary and coordination of the function of school and social organization has accelerated the modernization process of educational governance ability.

\section{The Realistic Dilemma Facing the Modernization of Educational Governance Ability under the Background of Big Data}

While recognizing the large degree of scientific data to enhance the scientific management of education at the same time cannot ignore the big data from another side for the efficiency of education governance challenges. Large data itself contains massive information, variety, complex structure and other characteristics, which requires the main body of education in the information collection link into human, material, financial, time and other costs, increasing the cost of investment on the efficiency of education directly constitute a challenge. On the other hand, from the test of educational governance data screening. In the collected mass education governance data, not all data are true and reliable, complete and correct, but also need to "fake true", that is, from the screening of real, effective and complete data, remove the wrong, false, incomplete data.

"Information silos are due to data standards and other reasons, resulting in different information systems between the data can not be compatible, thus forming a one island." The formation of information silos will inevitably lead to different educational governance in the effective information sharing in trouble, because they can not get the relevant information, not only affected the scientific decision-making of the main level of education, but also caused unnecessary waste of resources, especially in the Inside the government and within the school is more obvious. At present, the independent operation of various departments within the government leads to huge differences in the processing and application of data information, the formation of different information processing standards, formats, etc., different departments of "their own", a direct result of "data barriers" It cannot achieve effective data exchange and transmission of information. Therefore, the educational administration departments in the "data interaction" with other departments also face the corresponding obstacles, not only the impact of the macro-planning of the education sector, but also hindered the different sectors of the education sector synergies.

Large data age of the relevant data mining, screening, processing, storage and other means put forward high demands to encourage the appropriate technical services used in educational 
governance practice embodies a combination of information science and education management of new education governance thinking. Among them, the human resources as a large data application of the bearer, the combination of large data and educational governance play a key role. But at present, Chinese education in the use of large data on the face of the shortage of talent lead to large data difficult to achieve scientific management of education services. Related research shows that "in terms of policy, first of all to solve the large data mining and learning analysis of analysts and managers of the serious shortage. According to the McKinsey report estimates that the United States each industry a total of 14 to 19 million high-end data analysis experts, and the lack of 1.5 million large data analysts and managers.

\section{The Way to Promote the Modernization of Educational Governance Ability under the Background of Big Data}

To make the big data become the "weapon" of the modernization of educational governance ability, it is necessary to establish the consciousness of large data, and to guide the modernization of educational governance with data management thinking. First, the subject of education should establish data application awareness, attention to the role of data in the governance process. In the process of educational governance, the government should use the data in education and social related fields as the basic basis for decision-making. It will change the wrong behavior of the past by relying on subjective will to control education. The school should strengthen the collection and analysis of relevant data inside and outside the system and as the basic basis of internal governance and external adaptation to improve the effectiveness of educational governance; social organizations with their own advantages can grasp the government, the school can not grasp part of the data, so as to participate in education governance to make up for the lack of government and school conditions. Second, the main body of education governance should establish the concept of open sharing of data.

Government departments, schools, etc. should establish a unified data transmission, identification, storage and other operating standards, with a unified standard system to maintain the relevant government departments, schools and other internal data governance in the sharing, sustainability, and thus establish a valid of the internal data network system, to achieve government, schools and other data in the internal coordination of governance. On the other hand, strengthen the government, the school and the social organization between the data platform construction. First of all, the government, schools and social organizations should strengthen the collection, collation, storage and analysis of educational data, and strive to build their own basic database of educational governance, laying the foundation for the data management of the main body in the process of modernization of educational governance. Secondly, we will strengthen the integration of data resources between governments, between schools and between social organizations, and form a joint database with the scale of the scale, so as to provide data support for the rationality of diversified governance. At the same time, under the premise of establishing the concept of open sharing of data, the author carries out the integration and operation of education data between different subjects and different fields, constructs the "big database" of educational governance, and builds the open system data exchange and sharing platform to realize the management Between the educational governance system and the social system between the data exchange and interactive sharing, to achieve education management capacity of the data and wisdom.

From the current policy plan has been introduced in July 2012 issued by the State Council, "' second five "national strategic emerging industry development plan", in January 2013 Ministry of Industry and Information Technology "on the data center construction layout guidance Opinions "issued by the State Council in August 2015 issued by the State Council on the issuance of action to promote the development of large data platform for the notice" and in March 2016 the National People's Congress adopted the "People's Republic of Chinese national economic and social development thirteenth five-year plan" In the "national big data strategy" part, all of Chinese large data development of the macro strategic planning. However, Chinese lack of large-scale data at the legal level of the relevant norms. The future, China should speed up the big data legislation, with a 
specific legal system to regulate the development of large data. In the field of education governance, the government and universities should formulate corresponding data development plan under the guidance of the top design of the national large data. At the same time, in the areas with the conditions, the time is ripe, and actively explore the large data of educational governance Application and development of institutionalized and legalized path, improve the education and management of large data and its application of the legal and regulatory system to improve the system of large data law and system standard data search, collection, collation, storage, application, sharing and protect the work, and guide the orderly development of big data of educational governance, and provide legal guarantee for improving the modernization level of educational governance ability.

\section{Conclusion}

At present, Chinese education management capacity modernization is facing the problem of insufficient technical support. The article takes the big data as the background to cut into the modernization of the educational governance ability and discover the big data to bring various opportunities for the modernization of the educational governance ability. However, under the background of large data, the modernization of educational governance capacity in China still faces many difficulties, such as the challenge of governance efficiency in the process of education governance, the obstruction of information island and the shortage of talent shortage and the lack of system design. Therefore, strengthening the thinking of data governance, strengthening the construction of educational governance database, exploring the mechanism of large data talent cultivation and highlighting the construction of large data law and system can be regarded as the path choice of modernization of educational governance ability under the background of large data.

\section{References}

[1] Wang Zhanjun, Xiao Hongying. Modernization of Departments in the Context of Large Data[J]. Higher Education Research. 2016 (03)

[2] Ma Zhongying. Double situation and path selection of university governance ability in large data era[J]. Chinese Adult Education. 2016 (01)

[3] Yuan Fang. Study on the Realization Path of Promoting the Improvement of Government Governance Capability with Large Data [J].Journal of Hebei Normal University. 2015 (06)

[4] Xu Xiaodong, Wang Jinhua, Bian Liang, Meng Qian. Higher education data governance research [J]. Higher Engineering Education Research 2015 (05)

[5] Yang Xianmini. Application Model and Policy Suggestion of Educational Large Data [J] .Computer Education Research 2015 (09)

[6] Tang Huangfeng, Tao Jianwu. Chinese national governance capacity building in the era of large data[J]. Exploration and Controversy 2014 (10) 